${ }^{\mathbf{1}}$ Laboratório de Macroecologia, Universidade Federal de Goiás - Campus Jataí, Jatai, GO, Brazil; ${ }^{2}$ Departamento de Ecologia, ICB, Universidade Federal de Goiás, Goiânia, GO, Brazil; ${ }^{3}$ Department of Ecology, University of Alcalá de Henares, Alcalá de Henares, Spain

\title{
Integrating phylogeny, environment and space to explore variation in macroecological traits of Viperidae and Elapidae (Squamata: Serpentes)
}

\author{
Levi Carina Terribile ${ }^{1}$, José Alexandre Felizola Diniz-Filho ${ }^{2}$, Matheus de Souza Lima-Ribeiro ${ }^{1}$ and Miguel Ángel \\ RODRÍGUEZ ${ }^{3}$
}

\begin{abstract}
We used eigenvector mapping in space and phylogeny to investigate the relationships among space, phylogeny and environment on body size and range size variation across two groups of venomous snakes - Viperidae and Elapidae - from the New World. Data on species geographic range sizes, maximum body sizes and phylogenetic relationships were compiled from the available literature. The distributional data were also used to calculate the latitudinal and longitudinal midpoint and the environmental centroids for each species. The eigenvectors extracted from the pair wise spatial and phylogenetic distance matrices were integrated with environmental variables into a method of variation partitioning where the variation in each trait was quantitatively attributed to 'pure' and/or shared effects of phylogeny, environment and space. Our results showed that variation in body size was predominantly determined by phylogeny in both groups of snakes. For Viperidae, we found that pure 'effects' of phylogeny were the strongest, indicating that most of the body size evolution that was phylogenetically determined in this group occurred independently of environment and geographical proximity. Regarding range sizes, pure phylogenetic influences were very low in both groups, whereas the largest single fraction of explained variation corresponded to overlapped influences of the three sets of predictors, especially for Elapidae. Along with this, we found evidence that niche conservatism is an important processes underlying variation in body size and range size in both groups of snakes.
\end{abstract}

Key words: Viperidae - Elapidae - body size - range size - niche conservatism - macroecology

\section{Introduction}

Investigating variation in ecological traits is a primary goal in ecology and evolution. In the last two decades, the emerging field of macroecology has made valuable contributions to identifying and elucidating patterns of variation in traits at large spatial scales. Some of the most commonly studied macroecological patterns include the geographic variation in range size (Lyons and Willig 1997; Reed 2003), the geographic variation in body size (Blackburn and Gaston 1996; Bakker and Kelt 2000; Smith et al. 2004) and the relationship between body size and geographic range size (Blackburn and Gaston 2001; Geraghty et al. 2007). Several factors have been included as determinants of range size variation, such as current speciesspecific traits (i.e. body size or dispersal and establishment abilities; (e.g. Böhning-Gaese et al. 2006)), historical speciesspecific factors (e.g. phylogenetic age of lineages, Webb and Gaston 2003; Böhning-Gaese et al. 2006) or climate (Letcher and Harvey 1994; Gaston 2003; Hawkins and Diniz-Filho 2006). For instance, the observation that species inhabiting higher latitudes have broader geographical extents (Rapoport's Rule, Stevens 1989) has been associated with their need to withstand larger temporal variability in climatic conditions than species living at lower latitudes (Stevens 1989, 1996; Hecnar 1999; Reed 2003; but see Hawkins and Diniz-Filho 2006 for an alternative explanation). More recently, authors have raised the issue of the heritability of the size of geographical ranges (Webb and Gaston 2003, 2005; Hunt

Corresponding author: Levi Carina Terribile (levicarina@gmail.com) Contributing authors: José Alexandre Felizola Diniz-Filho (jafdinizfilho@, gmail.com), Matheus de Souza Lima-Ribeiro (paleo ribeiro@yahoo. com.br), Miguel Ángel Rodríguez (miguela.rodriguez@uah.es) et al. 2005; Waldron 2007), and for most groups of organisms it is still not clear which factors cause variation in range sizes across species.

Regarding spatial variation in body size, studies have widely focused on geographical differences exhibited within species (e.g. Ashton 2001), across species (e.g. Reed 2003; Adams and Church 2008) or in entire assemblages (Olalla-Tárraga et al. 2006; Diniz-Filho et al. 2009; Terribile et al. 2009a). These studies have frequently reported covariation between body size and environmental predictors, in some instances also addressing potential influences of phylogenetic relatedness (e.g. Diniz-Filho et al. 2009) or spatial proximity (e.g. Olalla-Tárraga et al. 2009), but very rarely (e.g. Freckleton and Jetz 2009) these three types of potential determinants of body size (i.e. environment, phylogeny and space) were analysed altogether, thus limiting our ability to understand what lies behind body size trends.

The statistical tests frequently used to look at cross-species variation in traits have the common assumption that the data represent independent samples from the same statistical distribution. However, when dealing with analyses of species traits in a geographically explicit context, ecologists must frequently overcome the 'problem' that observations in space are not independent from each other by the virtue of their spatial proximity (pseudoreplication in space, Legendre 1993; Diniz-Filho et al. 2003). This may occur because the biological processes influencing species distributions (e.g. dispersal, speciation or extinction) are spatially structured (Dormann et al. 2007), as are the environmental determinants themselves, thus generating apparent species' trait-environment concordance (Dormann et al. 2007; Legendre 1993; Peres-Neto 2006). While space can be considered a surrogate responsible for ecological structures (e.g. adaptive response to environment 
factors), it can also be a confounding variable leading to bias when analysing a process of particular interest (Dray et al. 2006; Griffith and Peres-Neto 2006; Dormann et al. 2007).

In a similar way, analyses of association between traits and environmental variables across species of a particular clade must deal with the fact that species are not biologically (and, hence, statistically) independent from one another, as they are part of a hierarchically structured phylogeny (pseudoreplications across species) (Felsenstein 1985; Harvey and Pagel 1991; Martins and Hansen 1996; Abouheif 1999). As both these sources of autocorrelation (spatial and phylogenetic) may occur simultaneously in macroecological datasets, a clear understanding of the ecological and evolutionary processes underpinning the differences in species traits requires that both sources of variation are taken into account in comparative analyses.

The limitations imposed by the need for independence in comparative analyses have been overcome by recent methods that allow for simultaneous control of phylogenetic relatedness and spatial proximity in the analyses of traits. For instance, Diniz-Filho et al. (2007) partitioned the evolutionary and ecological components of interspecific body size variation and analysed them in a geographically explicit context by combining 'phylogenetic eigenvector filtering' (PVR, developed by Diniz-Filho et al. 1998) with a simultaneous autoregressive model (see also Ramirez et al. 2008; Diniz-Filho et al. 2009; Olalla-Tárraga et al. 2010). Kühn et al. (2009) expanded these ideas by mapping phylogenetic information of a trait and extracting filters (called 'spatio-phylogenetic filters'), which were combined with spatial filters (Borcard and Legendre 2002) in a multiple regression framework. Freckleton and Jetz (2009) also provided a method to simultaneously estimate spatial and phylogenetic influences on trait variation in a cross-species approach, using a GLM under a Brownian motion model for species diversification. More recently, Safi and Pettorelli (2010) used phylogenetic and spatial filters extracted from pairwise matrices of phylogenetic and geographical distances, together with a set of environmental predictors, to describe the independent influences of history, space and environment on the extinction risk of Carnivora.

Here, we use the unifying idea of eigenvector mapping in space and phylogeny (see Peres-Neto 2006; Safi and Pettorelli 2010) to investigate the relative contribution of space, phylogeny and environmental variables and their overlapping effects on body size and range size variation across Viperidae and Elapidae, two primarily tropical-subtropical groups of venomous snakes in the New World (see Terribile et al. 2009b). The use of the eigenvector filtering methods for controlling spatial and phylogenetic autocorrelation has received increasing acceptance in ecological analyses, and, despite criticisms (e.g. Rohlf 2001; Freckleton et al. 2011), recent reviews have suggested that these techniques are efficient for minimizing undesirable effects of autocorrelation on ecological variables (Diniz-Filho et al. 2007, 2012a; Bini et al. 2009). The approach we applied here provides new insights into the ecological and evolutionary factors underpinning the variation in traits of New World venomous snakes at the species level.

\section{Materials and methods}

\section{Species, phylogeny and environmental data}

We focused on Viperidae and Elapidae species inhabiting the mainland Americas, a region where species-level phylogenetic relationships are better resolved compared to other areas (e.g. Castoe et al. 2009;
Fenwick et al. 2009). The availability of phylogenetic information determined which species would be included in this study. For Viperidae, we manually assembled a composite phylogeny from the evolutionary hypotheses provided in Murphy et al. (2002), Castoe et al. (2005, 2009), Castoe and Parkinson (2006), Bryson et al. (2008), Fenwick et al. (2009) and Jadin et al. (2010). Based on these, we were able to include 108 species of $\approx 120$ continental viperids. Studies of phylogenetic relationships for Elapidae (e.g. Silva and Sites 2001) are scarcer than for Viperidae. Currently, the most inclusive phylogeny for New Word elapids is the consensus tree provided in Campbell and Lamar (2004), which include 43 species. We used Campbell and Lamar's phylogeny and added two species included in Di-Bernardo et al. (2007). It is important to note that time-dated phylogenies at low taxonomic levels are scarce for snakes, or do not include all species (e.g. Wüster et al. 2008; Castoe et al. 2009). So, our phylogenies are purely topological, constructed by setting branch lengths equal to one. Consequently, we are actually assuming a punctuated equilibrium model for evolutionary changes (see below).

Data on species distributions and body sizes, expressed as maximum total lengths in millimetres (e.g. Boback and Guyer 2003; Reed 2003), were obtained from Campbell and Lamar (2004); see also Terribile et al. 2009a for more details). Range maps were projected onto an equal area grid with a cell resolution of $110 \times 110 \mathrm{~km}$ covering the study area. The range size of each species was computed as its number of occurrences in the grid cells and this estimate along with the species' body size were $\log _{10}+1$ and $\log _{10}$ transformed, respectively, to correct for allometric effects and heteroscedasticity.

We also used eight environmental variables: potential evapotranspiration (PET), mean annual temperature (TEMP), total annual precipitation (PREC), actual evapotranspiration (AET), average monthly global vegetation index (GVI), range in elevation (ELEV), interaction between range in elevation and mean temperature (INT) and seasonality (SEASON) as predictors of body and range size variation across species. These variables were selected because they are related to several hypotheses proposed to explain geographic variation in body size (e.g. Olalla-Tárraga and Rodríguez 2007) and range size (e.g. Hawkins and Diniz-Filho 2006), as follows: PET and TEMP are linked to heat balance hypothesis (for body size), and physiological tolerances related to Rapoport effect; ELEV and INT are linked to the effects of habitat availability on both body and range size (see Rodríguez et al. 2008); PREC, AET and GVI are proxies for primary productivity, and seasonality for the variation of primary productivity throughout the year, which may be related to variation in body size (Olalla-Tárraga and Rodríguez 2007; Terribile et al. 2009a), and, at least indirectly through this trait, to range size (e.g. Brown and Maurer 1989; Gaston and Blackburn 1996). For further details on environmental data acquisition and calculation, see Rodríguez et al. (2008) and Terribile et al. (2009a).

\section{Extracting eigenvector maps and modelling}

We combined phylogenetic and spatial eigenvector filtering techniques with partial regression analysis to separate independent (or 'pure') and shared effects of phylogeny, spatial proximity (hereafter 'space') and environment on body size and range size variation.

For phylogenetic filtering, we used phylogenetic eigenvector regression (PVR), a technique developed by Diniz-Filho et al. (1998; see also Diniz-Filho et al. 2007, 2009, 2012b; Olalla-Tárraga et al. 2010) that allows estimating the amount of phylogenetic signal in trait variation and to take into account phylogenetic nonindependence among species in comparative analyses. Despite some criticisms (Rohlf 2001; Freckleton et al. 2011), PVR has been proved to be a very useful technique for comparative analysis (e.g. Martins et al. 2002), and whose performance does not differ from other comparative methods (e.g. Machac et al. 2011) and can be a flexible tool for analysing spatial and phylogenetic data (Kühn et al. 2009; Safi and Pettorelli 2010). Moreover, the PVR method was recently improved for evaluating quantitative deviations of trait evolution rate from neutral expectations (e.g. evolution under a Brownian motion model), through the 'phylogenetic signal-representation', or PSR curve (see details in Diniz-Filho et al. 2012b). 
PVR is based on the assumption that the phylogenetic relationships among species of a monophyletic group can be expressed as a set of eigenvectors obtained by means of a principal coordinates analysis (PCoA; Legendre and Legendre 1998) from a pairwise phylogenetic distance matrix. These eigenvectors (or phylogenetic filters) represent orthogonal variables accounting for phylogenetic relationships that can be included directly in multiple regression analyses as any other potential predictor of trait variation (e.g. along with other environmental and/or spatial variables; see below).

We selected the number of eigenvectors necessary to account for phylogenetic variation in body size and range size following DinizFilho et al. (2009; see also Diniz-Filho et al. 2012a). That is, for each snake group we regressed each trait against the set of eigenvectors explaining $>99 \%$ of the covariation in the phylogenetic distance matrices (i.e. the first 23 eigenvectors for Viperidae, and the first 29 for Elapidae), and then selected those significantly correlated $(\mathrm{p}<0.05)$ with each trait (see also Desdevises et al. 2003). Moreover, we regressed each trait against the selected eigenvectors and checked for the presence of residual autocorrelation in the OLS model, ensuring that the set of eigenvectors effectively account for phylogenetic variation, and that the residuals are independent and therefore express the unique variation of each species for the trait under study (see Gittleman and Kot 1990; Diniz-Filho et al. 2009, 2012a). Since we do not have branch lengths to evaluate evolutionary models underlying trait variation, we opted for this purely statistical description and modelling of phylogenetic structures, rather than more complex and 'model-based' approaches, such as that proposed by Freckleton and Jetz (2009).

For the generation of spatial filters we first calculated the spatial midpoint (i.e. the mean latitude and longitude) of the geographical range of each species and used the resulting midpoints to generate a matrix of Euclidean distances among species pairs (e.g. Freckleton and Jetz 2009). This matrix was then truncated and submitted to a Spatial Eigenvector Mapping (SEVM), which has been considered an efficient method for detecting and quantifying spatial patterns over a wide range of scales (Griffith 2003; Dormann et al. 2007; Bini et al. 2009). The eigenvectors (or spatial filters) derived from SEVM with positive eigenvalues reflect the spatial relationships among the analysed points (Borcard and Legendre 2002), with eigenvectors with high eigenvalues representing broad-scale variation, and eigenvectors with lower eigenvalues indicating fine-scale trends (Diniz-Filho and Bini 2005). Similar to the case of phylogenetic eigenvectors (see above), the eigenvectors from SEVM represent orthogonal variables accounting for space variation and can also be incorporated into multiple regression analyses of the studied traits. Here, we used the SEVM module from SAM v4.0 (Rangel et al. 2010) to select appropriate sets of spatial eigenvectors for the analysis of each trait. These were those that significantly correlated with the trait under study and, at the same time, efficiently minimized Moran's $I$ in trait residuals resulting from a multiple regression analysis that also included the set of environmental predictors (to avoid keeping spatial eigenvectors that were collinear and, hence, redundant with the environmental predictors).

We aimed to estimate the relative contribution of phylogeny, space and environment on the variation of body size and range size. For this, we integrated the two types of filters along with environmental variables into a method of variation partitioning ('varpart' package from $\mathrm{R}$ ), where the variation in each trait was quantitatively attributed to 'pure' and/or shared effects of phylogeny, environment and space (see Supporting Information, Fig. S1 for the representation of each variation component from partial regression).

Finally, it has been proposed that the relationship between geographical-range size and body size should be roughly triangular in a log-log scale, with few or no species of large body size having small range sizes (Brown and Maurer 1987, 1989; see also Diniz-Filho and Tôrres 2002; Diniz-Filho et al. 2005). Accordingly, we correlated range size and body size to investigate potential associations between these traits, and also used body size as a predictor of range size in the variation partitioning analysis. That is, in this case, variation in range size for each group of snakes was decomposed into independent and shared effects of four explanatory variables: environment, phylogeny, space and body size.

\section{Results and discussion}

\section{Eigenvector filtering and overall variance explained by the} models

Phylogenetic eigenvector selection notably reduced the number of eigenvectors needed to reflect the influence of phylogeny on the interspecific variation of body size and range size in both snake groups (to 8 and 4 eigenvectors, respectively, in Viperidae, and 5 and 3 in Elapidae). A similar reduction resulted from the selection of spatial eigenvectors (to 8 and 10 in Viperidae, and 5 and 5 in Elapidae), obtaining Moran's $I$ values for trait residuals in the first distance class of $<0.09$ in all cases (see Table S1, Supporting Information). This means that the spatial filters captured almost all spatially structured variation of each trait that was not associated with our environmental variables, including potential influences of other aspects of the environment not measured by these predictors (e.g. isthmus effects on range sizes in Central America, or peninsula effects in southern South America), and/or of biotic processes generating spatial autocorrelation in the traits (Legendre 1993; Peres-Neto 2006). The latter could have happened, for example, if speciation in particular areas had generated species that are similar in terms of their mobility, which, in turn, could have facilitated them to occupy ranges of similar size (Brown et al. 1996), or to exhibit similar body sizes if their ability to obtain food was determined by their vagility (see e.g. Huey and Pianka 1981; Secor and Nagy 1994; Madsen and Shine 2000).

Multiple regression models including the eigenvectors selected for each trait and all environmental variables explained more than half of the variance of body size and range size in both snake groups, although slightly more for Viperidae (body size: $60 \%$; range size: $69 \%$ ) than for Elapidae (body size: $54 \%$; range size: $57 \%$ ). The amounts of variance accounted for individually by each set of predictors (i.e. phylogenetic, spatial and environmental) were generally qualitatively similar for body size between snake groups but not for range size (Figs 1 and 2; see below).

\section{Body size}

Starting with body size, phylogeny was more important than space and, especially, environment as it was associated with about half of the cross-species variation of this trait in both groups (Viperidae: 54\%, Elapidae: 51\%; Figs 1a and 2a, respectively). These figures suggest that species have retained the body size of their ancestors in a similar degree than they have evolved independently of their ancestry. In spite of these similarities, variation partitioning of the association of the three sets of predictors with body size into shared and pure (i.e. controlling for the 'effects' of the other factors) components found some differences between the snake groups. For Viperidae, the pure 'effects' of phylogeny were the strongest (34\%; Fig. 1a), indicating that most of the body size evolution that was phylogenetically determined in this group occurred independently of environment and geographical proximity. Although this result differs from previous analyses of average body size in geographic space (the 'assemblage approach' of Gaston et al. 2008) in which body size variation was weakly associated with phylogeny (see Terribile et al. 2009a for details), it is in agreement with the observations of Martins et al. (2001) that some lineages of Neotropical pitvipers 

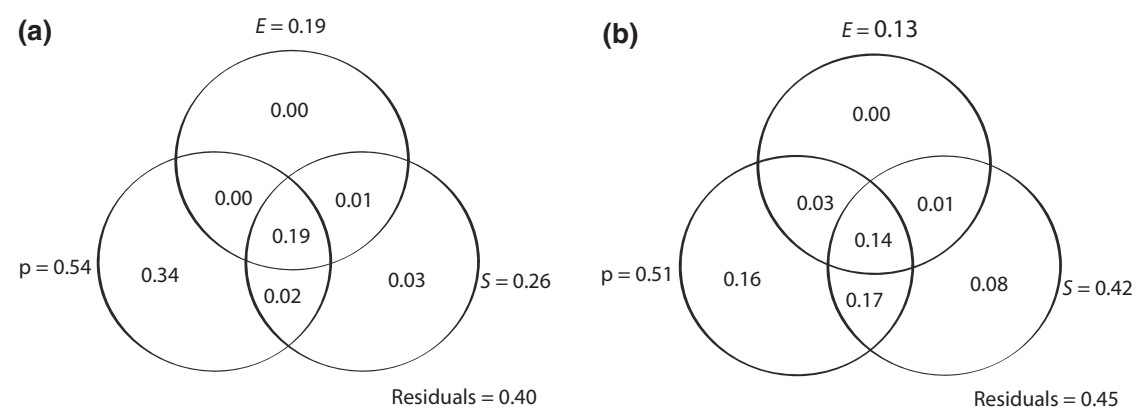

Fig. 1. Diagram of results from partial regression analysis for Viperidae (a) and Elapidae (b) body sizes. E - environment, $\mathrm{P}-$ phylogeny and $\mathrm{S}$ - space
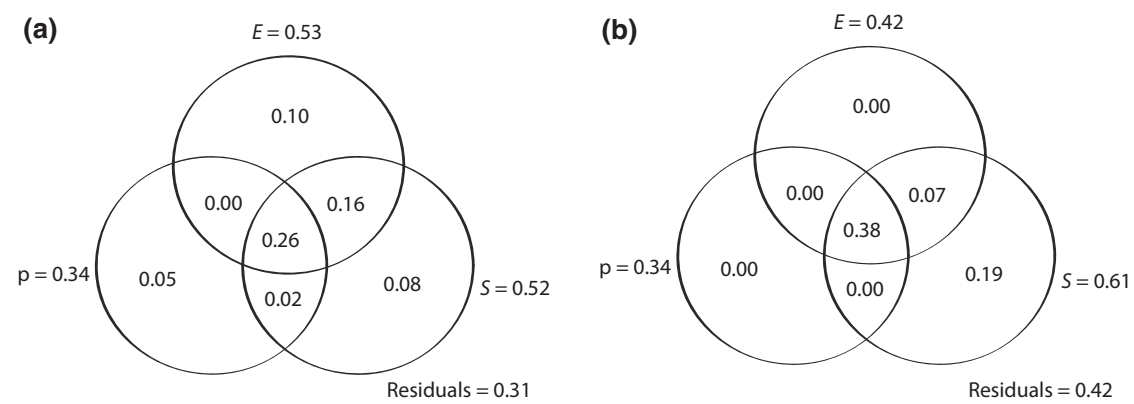

Fig. 2. Diagram of results from partial regression analysis for Viperidae (a) and Elapidae (b) range sizes. E - environment, $\mathrm{P}-$ phylogeny and $\mathrm{S}$ - space

maintain similar body sizes in spite of the variation in macrohabitats used by species.

In addition, our analysis also suggests a secondary role for niche conservatism in the evolution of body sizes, as most of the remaining variation associated with phylogeny $(19 \%)$ was described by shared 'effects' with environment and space. In turn, for the latter two sets of predictors, it is noteworthy that their pure and shared components that are independent of phylogeny were virtually negligible $(\leq 3 \%$ in all instances) compared with the unexplained variation that could not be attributed to any factor $(40 \%)$. This unexplained variance suggests that part of body size evolution probably occurred randomly and independently of ancestry, or at least due to factors not included in our analysis.

For Elapidae, pure 'effects' of phylogeny on body size were smaller $(16 \%)$ and comparable to those shared with environment and space $(14 \%)$ or with space only $(17 \%)$ (Fig. 1b). The results obtained for Elapidae also suggest some role of niche conservatism underpinning variation in this trait. Moreover, the overlap between phylogeny and space $(17 \%)$ points to that, in this case, niche conservatism may be reflecting a geographically constrained pattern of lineage diversification (i.e. close relatives living in close proximity due to geographical barriers or limited dispersion, see below), thus causing a positive association between trait and spatial distributions (Freckleton and Jetz 2009). However, since we cannot tell what lies within the spatial filters, we are unable to establish to what extent these results reflect a stronger influence of biogeography and/or niche conservatism in determining body size of Elapidae (which would be the case if the filters mainly reflected habitat conditions not measured by our variables).

\section{Range size}

Regarding range sizes, pure phylogenetic influences (i.e. independent of environment and space) were very low or nil in both groups, whereas the largest single fraction of explained variation resulting from the variation partitioning analysis corresponded to overlapped influences of the three sets of predictors, especially for Elapidae (Fig. 2a,b). This suggests a tendency for phylogenetically closely related species to spread across ranges of similar sizes and environmental conditions that overlap geographically or are located nearby. For example, this could reflect that species inhabiting temperate areas tend to show larger ranges than tropical species (as proposed by climate-driven explanations of Rapoport's Rule) (e.g. see Reed 2003; Fernández and Vrba 2005; Hawkins and Diniz-Filho 2006 and references therein) and/or that montane species tend to exhibit smaller ranges than lowland species (Hawkins and Diniz-Filho 2006; see also Rodríguez et al. 2008). Moreover, given that this phylogenetically structured variation overlapped with environmental 'effects', these results also suggest an influence of niche conservatism in determining range sizes, which would be stronger for Elapidae (see below).

Similarly, niche conservatism (spatially structured) was also important for range size of Viperidae, as it explained $26 \%$ of variation. However, focusing on the environmental influences that are independent of phylogeny (i.e. pure plus shared with space), it is noteworthy that they also accounted for an equal portion of range size variation $(10 \%+16 \%$; see Fig. $2 a)$. This cannot be attributed to niche conservatism (as phylogeny was not involved in this variance fraction), but rather suggests that the tendency for species with similar range sizes to occur in similar environmental conditions described above also exists 
in this group independently of phylogenetic relatedness. In other words, it is possible that unrelated species were restricted historically (by geographic barriers, or other factors related to the 'history of place', see Brown et al. 1996) to the same geographic areas and, hence, environmental constraints and that the similarity in the size of their ranges was a consequence of the development of equivalent adaptations by them. Our results also suggest that potential explanations associated with Rapoport's Rule and/or mountains versus lowland effects on range sizes also occur in viperids irrespective of their ancestry.

For Elapidae, most part of variation in range sizes $(38 \%)$ was explained by shared effects of phylogeny, environment and space (Fig. 2b). This is an important evidence of niche conservatism and confirms a tendency for New World elapids to retain ancestral characteristics (see Silva and Sites 2001; Di-Bernardo et al. 2007). Moreover, this tendency, when matched with the spatial component, suggests that biotic constraints (e.g. limited dispersion ability) may have forced sister species to occur near each other. A potential evidence of this is that New World elapids have a restricted distribution in the Neotropical region (when compared with viperids), with most of the species occurring in the north of South America (see Terribile et al. 2009b). The remaining largest fraction of the variation captured by the filters $(19 \%)$ could also reflect a Rapoport pattern not driven by climate (see Gaston et al. 1998), although whether this is true, or if there were other factors involved cannot be established, as the filters do identify a tendency for elapids with similar range size to co-occur spatially, but give no clue about what phenomena underlie this trend.

The correlation between range size and body size was similar and moderate in both groups (Fig. 3), lending some support for the notion that larger species tend to develop larger ranges. This posed the question of to what extent the observed phylogenetic influences on the cross-species variation of range sizes could be reflecting phylogenetic determination of body sizes. This was investigated including body size as an additional predictor of range size in our variation partitioning analyses. Overall, we found that, out of the $34 \%$ of range size variance described by phylogeny in both groups, body size was associated with $21 \%$ in Viperidae, and $14 \%$ in Elapidae, which suggests some role of body size in the observed phylogenetic signal of range sizes, especially for Viperidae (see Supporting Information Table S2 for partial regression results). Additionally, it is to be noted that most of these effects of body size overlapped with influences of environment in both groups, suggesting a link between niche conservatism and range sizes through body sizes. For instance, related species may have similar body sizes if they evolved under similar climatic constraints (Ramirez et al. 2008), which consequently can lead to similar range sizes. In fact, recent studies have showed that signals of range size heritability may emerge when related species share climatic tolerances, as well as habitat and environmental preferences (Mouillot and Gaston 2009; Machac et al. 2011). Thus, phylogenetically conserved traits such as body size may eventually lead to range size heritability, which have important implications for our understanding of body and range size association.

\section{Synthesis}

Our goal was to evaluate the simultaneous effects of phylogeny, environment and geographic space on variation of body size and range size of Viperidae and Elapidae snakes. Our
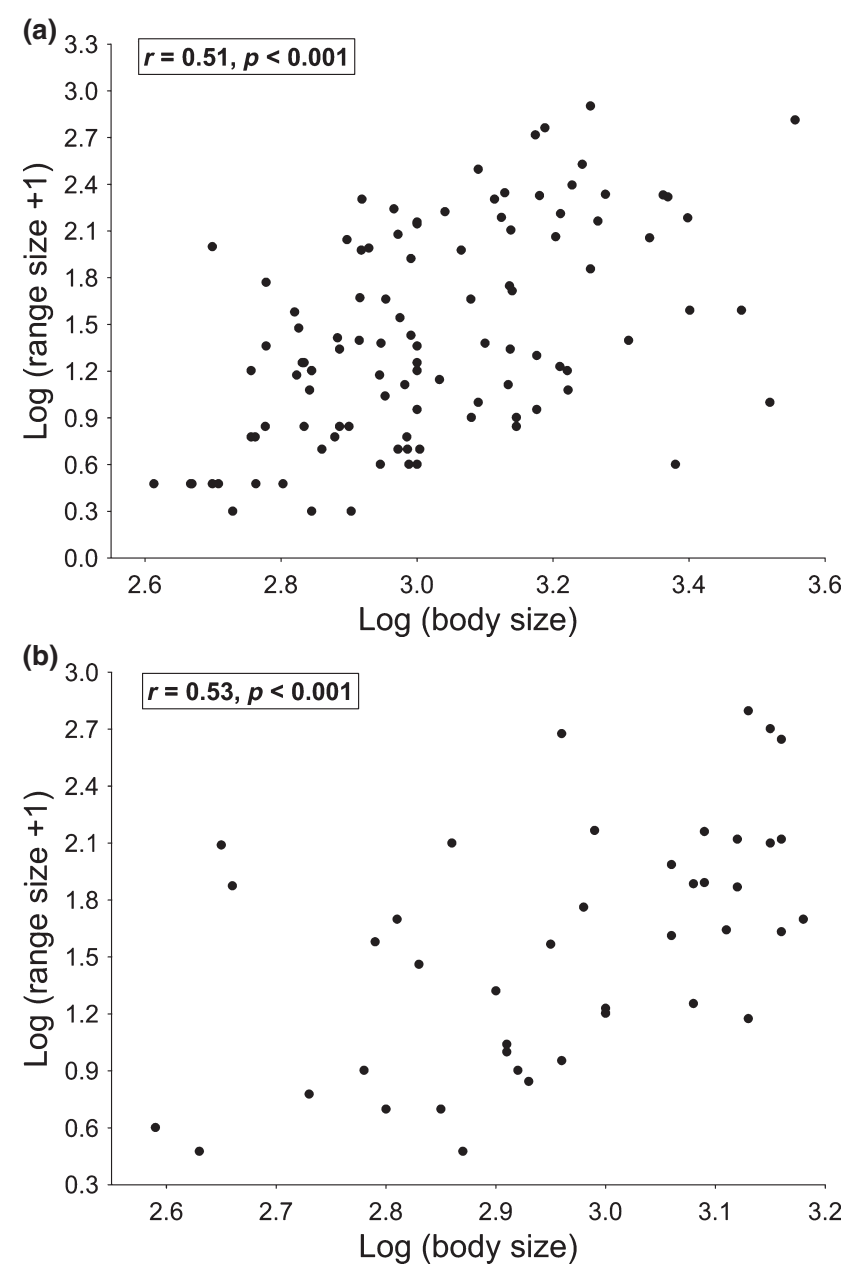

Fig. 3. Relationship between geographic range size and body size, after logarithmic transformation, for the New World Viperidae (a) and Elapidae (b)

approach of mapping phylogenetic and spatial eigenvectors enabled us to explore how phylogenetic and spatial effects, along with the environment, simultaneously shaped the evolution of these traits. Our results indicated that body size of New World venomous snakes is predominantly influenced by phylogeny. Moreover, part of this variation showed important evidence for niche conservatism, which suggests the tendency of related species to retain ecological traits over time. These findings have important implications, for example, for conservation of species in the face of global change (Wiens and Graham 2005; Wiens et al. 2010), since species with conserved niches may struggle to adapt to changing environments and could be eventually driven to extinction (Peterson et al. 2002; Cooper et al. 2011).

Some evidence of niche conservatism was also observed in range size, although the importance of phylogeny for this trait was negligible. Overall, changes in the range size of these snakes seem to have been driven by abiotic factors, i.e. space (in the case of Elapidae) and/or climate (in the case of Viperidae). Finally, our analyses also showed that there is not a simple relationship between geographic range size and body size of viperids and elapids. Instead, such association may be the result of complex interactions among several other biological characteristics linked to species geographic range (i.e. abundance, body size, life history characteristics). 


\section{Acknowledgements}

We are grateful to Kamran Safi and Ingolf Kühn for many useful suggestions that improved early versions of the manuscript. We also thank Bradford A. Hawkins for revision and valuable comments. L.C. Terribile thanks the University of Alcalá de Henares for their hospitality during the analyses of the data. The study was supported by the Spanish Fundación Carolina (Movilidad de Profesores Brasileños) and by CNPq (Process no 473788/2009-8). Work by J. A. F. Diniz-Filho is supported by CNPq productivity fellowship, and by $\mathrm{M}$. Á. Rodríguez by the Spanish Ministry of Science and Innovation (grant CGL2010-22119).

\section{Resumen}

Integrando la filogenia, el ambiente y el espacio para explorar la variación en caracteres macroecológicos en Viperidae y Elapidae (Squamata: Serpentes)

En este trabajo hemos utilizado el conocido método de mapeado de autovectores espaciales y filogenéticos para investigar la contribución relativa del espacio, la filogenia y el ambiente, y de sus efectos combinados, sobre los tamaños de cuerpo y rango de distribución de dos grupos de serpientes venenosas - Viperidae y Elapidae - en el Nuevo Mundo. Los datos sobre tamaños de rango de distribución, tamaños máximos de cuerpo y filogenias fueron extraídos de la literatura especializada. Los datos de distribución se utilizaron para calcular el punto medio de la distribución y el centroide ambiental para cada especie. Autovectores obtenidos a partir de matrices de distancias espaciales y distancias filogenéticas fueron incluidos junto con las variables ambientales en modelos de regresión parcial de los tamaños corporales y de rango de ambos grupos, y la variación de estos caracteres fue atribuida cuantitativamente a efectos individuales y combinados de la filogenia, el ambiente y el espacio. Los resultados mostraron que la variación del tamaño corporal está explicada principalmente por la filogenia en los dos grupos de serpientes. En Viperidae se observó que los efectos puros de la filogenia son más fuertes, indicando que la mayor parte de la evolución del tamaño de cuerpo en este grupo ha ocurrido independientemente del ambiente y la proximidad geográfica. Con respecto al tamaño de rango, los efectos filogenéticos puros fueron reducidos en los dos grupos, mientras que la mayor parte de la variación en este carácter fue explicada por el efecto combinado de las tres variables predictoras, especialmente para Elapidae. Además, encontramos evidencias de que la conservación de nicho es un importante condicionante de la variación de los tamaños corporales y de rango de distribución en ambos grupos de serpientes.

\section{References}

Abouheif E (1999) A method for testing the assumption of phylogenetic independence in comparative data. Evol Ecol Res 1:895-909.

Adams DC, Church JO (2008) Amphibians do not follow Bergmann's rule. Evolution 62:413-420.

Ashton KG (2001) Body size variation among mainland populations of the western rattlesnake (Crotalus viridis). Evolution 55:25232533.

Bakker VJ, Kelt DA (2000) Scale-dependent patterns in body size distributions of neotropical mammals. Ecology 81:3530-3547.

Bini LM, Diniz-Filho JAF, Rangel TFLVB, Akre TSB, Albaladejo RG, Albuquerque FS, Aparicio A, Araújo MB, Baselga A, Beck J, Bellocq MI, Böhning-Gaese K, Borges PAV, Castro-Parga I, Chey VK, Chown SL, Marco P Jr, Dobkin DS, Ferrer-Castán D, Field R, Filloy J, Fleishman E, Gómez JF, Hortal J, Iverson JB, Kerr JT, Kissling WD, Kitching IJ, León-Cortés JL, Lobo JM, Montoya D, Morales-Castilla I, Moreno JC, Oberdorff T, Olalla-Tárraga MÁ, Pausas JG, Qian H, Rahbek C, Rodríguez MÁ, Rueda M, Ruggiero A, Sackmann P, Sanders NJ, Terribile LC, Vetaas OR, Hawkins BA (2009) Coefficient shifts in geographical ecology: an empirical evaluation of spatial and non-spatial regression. Ecography 32:1-12.

Blackburn TM, Gaston KJ (1996) Spatial patterns in the body sizes of bird species in the New World. Oikos 77:436-446.
Blackburn TM, Gaston KJ (2001) Linking patterns in macroecology. J Anim Ecol 70:338-352.

Boback SM, Guyer C (2003) Empirical evidence for an optimal body size in snakes. Evolution 57:345-351.

Böhning-Gaese K, Caprano T, van Ewijk K, Veith M (2006) Range size: disentangling current traits and phylogenetic and biogeographic factors. Am Nat 164:556-567.

Borcard D, Legendre P (2002) All-scale spatial analysis of ecological data by means of principal coordinates of neighbour matrices. Ecol Modell 153:51-68.

Brown JH, Maurer BA (1987) Evolution of species assemblages: effects of energetic constraints and species dynamics on the diversification of the North American avifauna. Am Nat 130:1-17.

Brown JH, Maurer BA (1989) Macroecology: the division of food and space among species on continents. Science 243:1145-1150.

Bryson RW, Oca AN-M, Velasco JR (2008) Phylogenetic position of Porthidium hespere (Viperidae: Crotalinae) and phylogeography of arid-adapted hognosed pitvipers based on mitochondrial DNA. Copeia 1:172-178.

Brown JH, Stevens GC, Kaufman DM (1996) The geographic range: size, shape, boundaries, and internal structure. Annu Rev Ecol Syst 27:597-623.

Campbell JA, Lamar WW (2004) The Venomous Reptiles of the Western Hemisphere, Vol I and II. Cornell University Press, New York.

Castoe TA, Parkinson CL (2006) Bayesian mixed models and the phylogeny of pitvipers (Viperidae: Serpentes). Mol Phylogenet Evol 39:91-110

Castoe TA, Sasa MM, Parkinson CL (2005) Modeling nucleotide evolution at the mesoscale: the phylogeny of the Neotropical pitvipers of the Porthidium group (Viperidae: Crotalinae). Mol Phylogenet Evol 37:881-898.

Castoe TA, Daza JM, Smith EN, Sasa MM, Kuch U, Campbell JA, Chippindale PT, Parkinson CL (2009) Comparative phylogeography of pitvipers suggests a consensus of ancient Middle American highland biogeography. J Biogeogr 36:88-103.

Cooper N, Freckleton RP, Jetz W (2011) Phylogenetic conservatism of environmental niches in mammals. Proc Biol Sci 278:2384-2391.

Desdevises Y, Legendre P, Azouzi L, Morand L (2003) Quantifying phylogenetically structured environmental variation. Evolution 57:2647-2652.

Di-Bernardo M, Borges-Martins M, Silva NJ Jr (2007) A new species of coralsnake (Micrurus: Elapidae) from southern Brazil. Zootaxa 1447:1-26.

Diniz-Filho JAF, Bini LM (2005) Modelling geographical patterns in species richness using eigenvector-based spatial filters. Glob Ecol Biogeogr 14:177-185.

Diniz-Filho JAF, Carvalho P, Bini LM, Tôrres NM (2005) Macroecology, geographic range size-body size relationship and minimum viable population analysis for New World Carnivora. Acta Oecologica 27:25-30.

Diniz-Filho JAF, Tôrres NM (2002) Phylogenetic comparative methods and the geographic range size - body size relationship in New World terrestrial Carnivora. Evol Ecol 16:351-367.

Diniz-Filho JAF, Sant'Ana CDR, Bini LM (1998) An eigenvector method for estimating phylogenetic inertia. Evolution 52:1247-1262.

Diniz-Filho JAF, Bini LM, Bradford BA (2003) Spatial autocorrelation and red herrings in geographical ecology. Glob Ecol Biogeogr 12:53-64.

Diniz-Filho JAF, Bini LM, Rodríguez MÁ, Rangel TFLVB, Hawkins BA (2007) Seeing the forest for the trees: partitioning ecological and phylogenetic components of Bergmann's rule in European Carnivora. Ecography 30:598-608.

Diniz-Filho JAF, Rodríguez MA, Bini LM, Olalla-Tárraga MA, Cardillo M, Nabout JC, Hortal J, Hawkins BA (2009) Climate history, human impacts and global body size of Carnivora (Mammalia: Eutheria) at multiple evolutionary scales. J Biogeogr 36:22222236.

Diniz-Filho JAF, Bini LM, Rangel TF, Morales-Castilla I, OlallaTárraga MÁ, Rodríguez MÁ, Hawkins BA (2012a).On the selection of phylogenetic eigenvectors for ecological analyses,Ecography in press. 
Diniz-Filho JAF, Rangel TF, Santos T, Bini LM (2012b) A modelbased interpretation for phylogenetic eigenvector regression. Evolution, in press.

Dormann CF, McPherson JM, Araújo MB, Bivand R, Bolliger J, Carl G, Davies RG, Hirzel A, Jetz W, Kissling WD, Kühn I, Ohlemüller R, Peres-Neto PR, Reineking B, Schröder B, Schurr FM, Wilson R (2007) Methods to account for spatial autocorrelation in the analysis of species distributional data: a review. Ecography 30: 609-628.

Dray S, Legendre P, Peres-Neto PR (2006) Spatial modelling: a comprehensive framework for principal coordinate analysis of neighbour matrices (PCNM). Ecol Modell 196:483-493.

Felsenstein J (1985) Phylogenies and the comparative method. Am Nat 125:1-15.

Fenwick AM, Gutberlet RL Jr, Evans JA, Parkinson CL (2009) Morphological and molecular evidence for phylogeny and classification of South American pitvipers, genera Bothrops, Bothriopsis, and Bothrocophias (Serpentes: Viperidae). Zool J Linn Soc Lond 156:617-640.

Fernández MH, Vrba ES (2005) Rapoport effect and biomic specialization in African mammals: revisiting the climatic variability hypothesis. J Biogeogr 32:903-918.

Freckleton RP, Jetz W (2009) Space versus phylogeny: disentangling phylogenetic and spatial signals in comparative data. Proc Biol Sci 276:21-30.

Freckleton RP, Cooper N, Jetz W (2011) Comparative methods as a statistical fix: the dangers of ignoring an evolutionary model. Am Nat 178:E10-E17.

Gaston KJ (2003) The Structure and Dynamics of Geographic Ranges. Oxford University Press, New York.

Gaston KJ, Blackburn TM (1996) Range size-body size relationships: evidence of scale dependence. Oikos 74:479-485.

Gaston KJ, Blackburn TM, Spicer JI (1998) Rapoport's rule: time for an epitaph? Trends Ecol Evol 13:70-74.

Gaston KJ, Chown SL, Evans KL (2008) Ecogeographical rules: elements of a synthesis. J Biogeogr 35:483-500.

Geraghty MJ, Dunn RR, Sanders NJ (2007) Body size, colony size, and range size in ants (Hymenoptera: Formicidae): are patterns along elevational and latitudinal gradients consistent with Bergmann's Rule? Myrmecol News 10:51-58.

Gittleman JL, Kot M (1990) Adaptation: statistics and a null model for estimating for phylogenetic effects. Syst Zool 39:227-241.

Griffith DA (2003) Spatial Autocorrelation and Spatial Filtering: Gaining Understanding Through Theory and Visualization. Springer-Verlag, New York.

Griffith DA, Peres-Neto PR (2006) Spatial modeling in ecology: the flexibility of eigenfunction spatial analyses. Ecology 87:2603-2613.

Harvey PH, Pagel MD (1991) The Comparative Method in Evolutionary Biology. Oxford University Press, New York.

Hawkins BA, Diniz-Filho JAF (2006) Beyond Rapoport's rule: evaluating range size patterns of New World birds in a twodimensional framework. Glob Ecol Biogeogr 15:461-469.

Hecnar SJ (1999) Patterns of turtle species' geographic range size and a test of Rapoport's rule. Ecography 22:436-446.

Huey RB, Pianka ER (1981) Ecological consequences of foraging mode. Ecology 62:991-999.

Hunt G, Roy K, Jablonski D (2005) Species-level heritability reaffirmed: a comment on "On the heritability of geographic range sizes". Am Nat 166:129-135.

Jadin RC, Gutberlet RL Jr, Smith EN (2010) Phylogeny, evolutionary morphology, and hemipenis descriptions of the Middle American jumping pitvipers (Serpentes: Crotalinae: Atropoides). J Zoolog Syst Evol Res 48:360-365.

Kühn I, Nobis MP, Durka W (2009) Combining spatial and phylogenetic eigenvector filtering in trait analysis. Glob Ecol Biogeogr 18:745-758.

Legendre P (1993) Spatial autocorrelation: trouble or new paradigm? Ecology 4:1659-1673.

Legendre P, Legendre L (1998) Numerical Ecology. Elsevier Science, Amsterdam.

Letcher AJ, Harvey PH (1994) Variation in geographical range size among mammals of the Paleartic. Am Nat 144:30-42.
Lyons SK, Willig MR (1997) Latitudinal patterns of range size: methodological concerns and empirical evaluations for New World bats and marsupials. Oikos 79:568-580.

Machac A, Zrzavy J, Storch D (2011) Range size heritability in carnivora is driven by geographic constraints. Am Nat 177:767779.

Madsen T, Shine R (2000) Silver spoons and snake body sizes: prey availability early in life influences long-term growth rates of freeranging pythons. J Anim Ecol 69:952-958.

Martins EP, Hansen TF (1996) A microevolutionary link between phylogenies and comparative data. In Harvey P, Smith JM, LeighBrown A (eds), New Uses for New Phylogenies. Oxford University Press, Oxford, pp 283-288.

Martins EP, Diniz-Filho JAF, Housworth EA (2002) Adaptive constraints and the phylogenetic comparative method: a computer simulation test. Evolution 56:1-13.

Martins M, Araujo MS, Sawaya RJ, Nunes R (2001) Diversity and evolution of macrohabitat use, body size and morphology in a monophyletic group of Neotropical pitvipers (Bothrops). J Zool 254:529-538.

Mouillot D, Gaston K (2009) Spatial overlap enhances geographic range size conservatism. Ecography 32:671-675.

Murphy RWJ, Fu AL, Feltham JV, Kovac V (2002) Phylogeny of the rattlesnakes (Crotalus and Sistrurus) inferred from sequences of five mitochondrial DNA genes. In: Höggren M, Schuett GW, Greene H, Douglas ME (eds), Biology of the Vipers. Eagle Mountain Publishing, Eagle Mountain, UT, pp 69-92.

Olalla-Tárraga MÁ, Rodríguez MÁ (2007) Energy and interspecific body size patterns of amphibian faunas in Europe and North America: anurans follow Bergmann's rule, urodeles its converse. Global Ecol Biogeogr 16:606-617.

Olalla-Tárraga M, Rodríguez M, Hawkins BA (2006) Broad-scale patterns of body size in squamate reptiles of Europe and North America. J Biogeogr 33:781-793.

Olalla-Tárraga MÁ, Diniz-Filho JAF, Bastos RP, Rodríguez MÁ (2009) Geographic body size gradients in tropical regions: water deficit and anuran body size in the Brazilian Cerrado. Ecography 32:581-590.

Olalla-Tárraga MÁ, Bini LM, Diniz-Filho JA, Rodríguez MÁ (2010) Cross-species and assemblage-based approaches to Bergmann's rule and the biogeography of body size in Plethodon salamanders of eastern North America. Ecography 33:362-368.

Peres-Neto PR (2006) A unified strategy for estimating and controlling spatial, temporal and phylogenetic autocorrelation in ecological models. Oecol Bras 10:105-119.

Peterson AT, Ortega-Huerta MA, Bartley J, Sanchez-Cordero V, Soberón J, Buddemeier RH, Stockwell DRB (2002) Future projections for Mexican faunas under global climate change scenarios. Nature 416:626-629.

Ramirez L, Diniz-Filho JA, Hawkins BA (2008) Partitioning phylogenetic and adaptive components of the geographical body-size pattern of New World birds. Glob Ecol Biogeogr 7:100-110.

Rangel TF, Diniz-Filho JAF, Bini LM (2010) SAM: a comprehensive application for Spatial Analysis in Macroecology. Ecography 33:4650.

Reed RN (2003) Interspecific patterns of species richness, geographic range size, and body size among New World venomous snakes. Ecography 26:107-117.

Rodríguez MÁ, Olalla-Tárraga MÁ, Hawkins BA (2008) Bergmann's rule and the geography of mammal body size in the Western Hemisphere. Glob Ecol Biogeogr 17:274-283.

Rohlf FJ (2001) Comparative methods for the analysis of continuous variables: geometric interpretations. Evolution 55:2143-2160.

Safi K, Pettorelli N (2010) Phylogenetic, spatial and environmental components of extinction risk in carnivores. Glob Ecol Biogeogr 19:352-362.

Secor SM, Nagy KA (1994) Bioenergetic correlates of foraging mode for the snakes Crotalus cerastes and Masticophis flagellum. Ecology 75:1600-1614.

Silva NJ Jr, Sites JW Jr (2001) Phylogeny of South American coral snakes (Elapidae: Micrurus) based on molecular characters. Herpetologica 57:1-22. 
Smith FA, Brown JH, Haskell JP, Lyons SK, Alroy J, Charnov EL, Dayan T, Enquist BJ, Ernest SKM, Hadly EA, Jones KE, Kaufman DM, Marquet PA, Maurer BA, Niklas KJ, Porter WP, Tiffney B, Willig MR (2004) Similarity of mammalian body size across the taxonomic hierarchy and across space and time. Am Nat 163:672691.

Stevens GC (1989) The latitudinal gradient in geographical range: how so many species coexist in the tropics. Am Nat 133:240-256.

Stevens GC (1996) Extending Rapoport's rule to Pacific marine fishes. J Biogeogr 23:149-154.

Terribile LC, Olalla-Tárraga MÁ, Diniz-Filho JA, Rodríguez MÁ (2009a) Ecological and evolutionary components of body size geographic variation of venomous snakes at the global scale. Biol J Linn Soc 98:94-109.

Terribile LC, Olalla-Tárraga MÁ, Morales-Castilla I, Rueda M, Vidanes RM, Rodríguez MA, Diniz-Filho JAF (2009b) Global richness patterns of venomous snakes reveal contrasting in influences of ecology and history in two different clades. Oecologia 159:617-626

Waldron A (2007) Null models of geographic range size evolution reaffirm its heritability. Am Nat 170:221-231.

Webb TJ, Gaston KJ (2003) On the heritability of geographic range sizes. Am Nat 161:555-566.

Webb TJ, Gaston KJ (2005) Heritability of geographic range sizes revisited: a reply to Hunt et al. Am Nat 166:136-143.

Wiens JJ, Graham CH (2005) Niche conservatism: integrating evolution, ecology, and conservation biology. Annu Rev Ecol Evol Syst 36:519-539.
Wiens JJ, Ackerly DD, Allen AP, Anacker BL, Buckley LB, Cornell HV, Damschen EI, Davies TJ, Grytnes J-A, Harrison SP, Hawkins BA, Holt RD, McCain CM, Stephens PR (2010) Niche conservatism as an emerging principle in ecology and conservation biology. Ecol Lett 13:1310-1324.

Wüster W, Peppin L, Pook CE, Walker DE (2008) A nesting of vipers: phylogeny and historical biogeography of the Viperidae (Squamata: Serpentes). Mol Phylogenet Evol 49:445-459.

\section{Supporting Information}

Additional supporting information may be found in the online version of this article:

Figure S1. Venn diagram representation of the process associated with body and range size variation. E, environment; $\mathrm{P}$, phylogeny; $\mathrm{S}$, space.

Table S1. Number of phylogenetic and spatial filters used in the partial regression analyses. Moran's $I$ of first distance classes are provided in parentheses.

Table S2. Variance partition model for range size.

Please note: Wiley Blackwell are not responsible for the content or functionality of any supporting information supplied by the authors. Any queries (other than missing material) should be directed to the corresponding author for the article. 